\title{
Current separation and upwelling over the southeast shelf of Vietnam in the South China Sea
}

\author{
Changsheng Chen, ${ }^{1,2}$ Zhigang Lai, ${ }^{1,3}$ Robert C. Beardsley, ${ }^{4}$ Qichun Xu, ${ }^{1}$ Huichan Lin, ${ }^{1}$ \\ and Nguyen Trung Viet ${ }^{5}$
}

Received 18 March 2011; revised 21 January 2012; accepted 30 January 2012; published 21 March 2012.

[1] The high-resolution, unstructured grid Finite-Volume Community Ocean Model

(FVCOM) was used to examine the physical mechanisms that cause current separation and upwelling over the southeast shelf of Vietnam in the South China Sea (SCS). Process-oriented experiments suggest that the southwesterly monsoon wind is a key physical mechanism for upwelling in that area but not a prerequisite to cause current separation. With no wind forcing, current separation in summer can occur as a result of the encounter of a southward along-shelf coastal current from the north and northeastward buoyancy-driven and stratified tidal-rectified currents from the southwest. The southward current can be traced upstream to the Hong River in the Gulf of Tonkin. This current is dominated by semigeostrophic dynamics and is mostly confined to the narrow shelf along the northern Vietnamese coast. The northeastward currents are generated by tidal rectification and are intensified by the Mekong River discharge and southwesterly monsoon wind forcing. The dynamics controlling this current are fully nonlinear, with significant contributions from advection and vertical turbulent mixing. Upwelling in the current separation zone can be produced by a spatially uniform constant wind field and can be explained using simple wind-induced Ekman transport theory. This finding differs from previous theory in which the regional dipole wind stress curl is claimed as a key mechanism for current separation and upwelling in this coastal region. Our SCS FVCOM, driven by the wind stress, river discharge, and tides, is capable of reproducing the location and tongue-like offshore distribution of temperature as those seen in satellite-derived sea surface temperature imagery.

Citation: Chen, C., Z. Lai, R. C. Beardsley, Q. Xu, H. Lin, and N. T. Viet (2012), Current separation and upwelling over the southeast shelf of Vietnam in the South China Sea, J. Geophys. Res., 117, C03033, doi:10.1029/2011JC007150.

\section{Introduction}

[2] Strong upwelling prevails along the southeast coast of Vietnam in the South China Sea (SCS) during summer (Figure 1). This upwelling is evident in satellite-derived sea surface temperature (SST) images as a cold water zone that extends offshore in the southward region (south of $12^{\circ}$ ) [Tang et al., 2004; Doktorgrades, 2008; Hai et al., 2010]. The spatial scale and intensity of the upwelling exhibit significant short-term (order of days) and seasonal variability (Figure 2). The temperature in the upwelling zone is

\footnotetext{
${ }^{1}$ School for Marine Science and Technology, University of Massachusetts Dartmouth, New Bedford, Massachusetts, USA.

${ }^{2}$ Marine Ecosystem and Environment Laboratory, College of Marine Science, Shanghai Ocean University, Shanghai, China.

${ }^{3}$ School of Marine Sciences, Sun Yat-Sen University, Guangzhou, China.

${ }^{4}$ Department of Physical Oceanography, Woods Hole Oceanographic Institution, Woods Hole, Massachusetts, USA.

${ }^{5}$ Department of Civil Engineering, Water Resource University, Hanoi, Vietnam.

Copyright 2012 by the American Geophysical Union. 0148-0227/12/2011JC007150
}

typically $\sim 24-25^{\circ} \mathrm{C}$, which is $\sim 3-5^{\circ} \mathrm{C}$ colder than the surrounding water. The physical processes driving the formation of this upwelling have been examined in both theoretical and numerical studies [e.g., Shaw and Chao, 1994; Xie et al., 2003; Gan and Qu, 2008]. These studies suggested that upwelling in that coastal region is a result of the response of the stratified ocean to the monsoon-induced local dipole wind stress curl in the coastal region with abrupt changes in bottom topography. The dipole wind stress curl causes an offshore current separation and thus upwelling over the coastal region where topographic contours diverge southward.

[3] We question this proposed mechanism for several reasons. The first is that the upwelling observed in the satellite-derived SST images appears as a local scale feature rather than a large-scale event. The second is that the flow in that region is driven by a more complex combination of dynamical processes than the wind-driven circulation. The third is that the dipole wind stress curl fields used in these previous studies were constructed using the NCEP reanalysis data with a horizontal resolution of $1.88^{\circ} \times 1.88^{\circ}$, which may overestimate the spatial scale of the wind stress curl owing to insufficient horizontal resolution. We have 


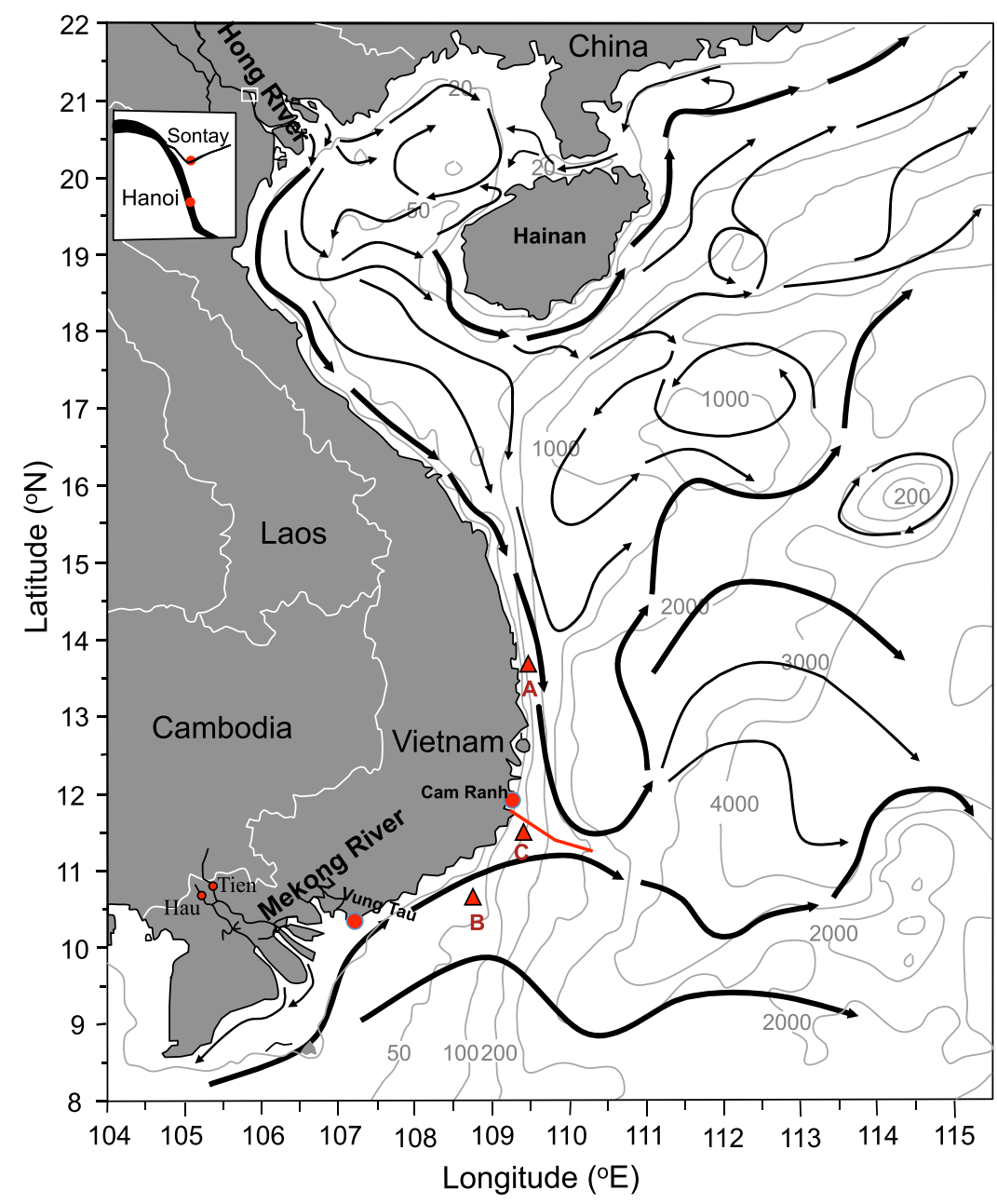

Figure 1. Map of the western South China Sea including the Gulf of Tonkin, Hainan Island, and Vietnam with the summertime circulation patterns schematized using the China coastal FVCOM model output and literature related to observations. The inset box is the boundary of the subfigure. Small red dots are the locations of the Sontay and Hanoi stations in the Hong River and the Tien and Hau stations in the Mekong River. Large red dots are the locations of tidal gauges at Cam Ranh and Vung Tau. Red triangles are the locations of sites A, B, and C used in Figures 12 and 13. Red line is the section used to draw Figure 10. Light blue lines denote the 20, 50, 100, 200, 1000, 2000, 3000, and $4000 \mathrm{~m}$ depth contours.

recalculated the surface wind stress curl field using the NCEP reanalysis 6 hourly wind data for the period 19952005. For August, for example, the spatial variation of the climatologically monthly averaged wind in the southwest coastal region is relatively small except for the difference between the land and ocean (Figure 3a). While it is not appropriate to calculate the wind stress curl over the sea using land data, the curl computed including land data did not produce a well-defined dipole structure, with a maximum curl value of only $\sim 1.6 \times 10^{-7} \mathrm{~Pa} / \mathrm{m}$ (Figure $3 \mathrm{~b}$ ). Using the Ekman pumping equation $w=\operatorname{curl}(\tau / \rho f)$ we estimated the maximum upwelling velocity to be $\sim 5.2 \times$ $10^{-4} \mathrm{~cm} / \mathrm{s}$, which seems too small to cause the upwelling features shown in the satellite-derived SST images (Figure 2).

[4] After previous studies were conducted, the highresolution $\left(0.25^{\circ} \times 0.25^{\circ}\right) 6$ hourly multisatellite-derived "blended" wind product became available for the 1995-2005 period [Zhang et al., 2006]. The resulting wind stress curl does show a well-defined dipole structure off the southeast coast of Vietnam (Figures 3c-3d), but the maximum curl value $\left(\sim 3.8 \times 10^{-7} \mathrm{~Pa} / \mathrm{m}\right)$ is in the same order of magnitude as that found in the NCEP wind stress curl field. The vertical velocity estimated by Ekman pumping is $\sim 1.2 \times$ $10^{-3} \mathrm{~cm} / \mathrm{s}$, which is a factor of two larger than that produced by the NCEP wind stress curl. The northeast-oriented boundary line between negative and positive stress curl, however, is located far south $(\sim 80-200 \mathrm{~km})$ relative to the location where the coldest upwelling water is observed in the satellite-derived SST images. If this wind stress curl also drives the current separation, then in this case, upwelling does not appear as a feature in the current separation zone.

[5] Our analysis of previous studies in this region raises two questions here: (1) could upwelling be driven by a spatially uniform wind and (2) could the current separation occur in summer with absence of wind forcing? The contribution 

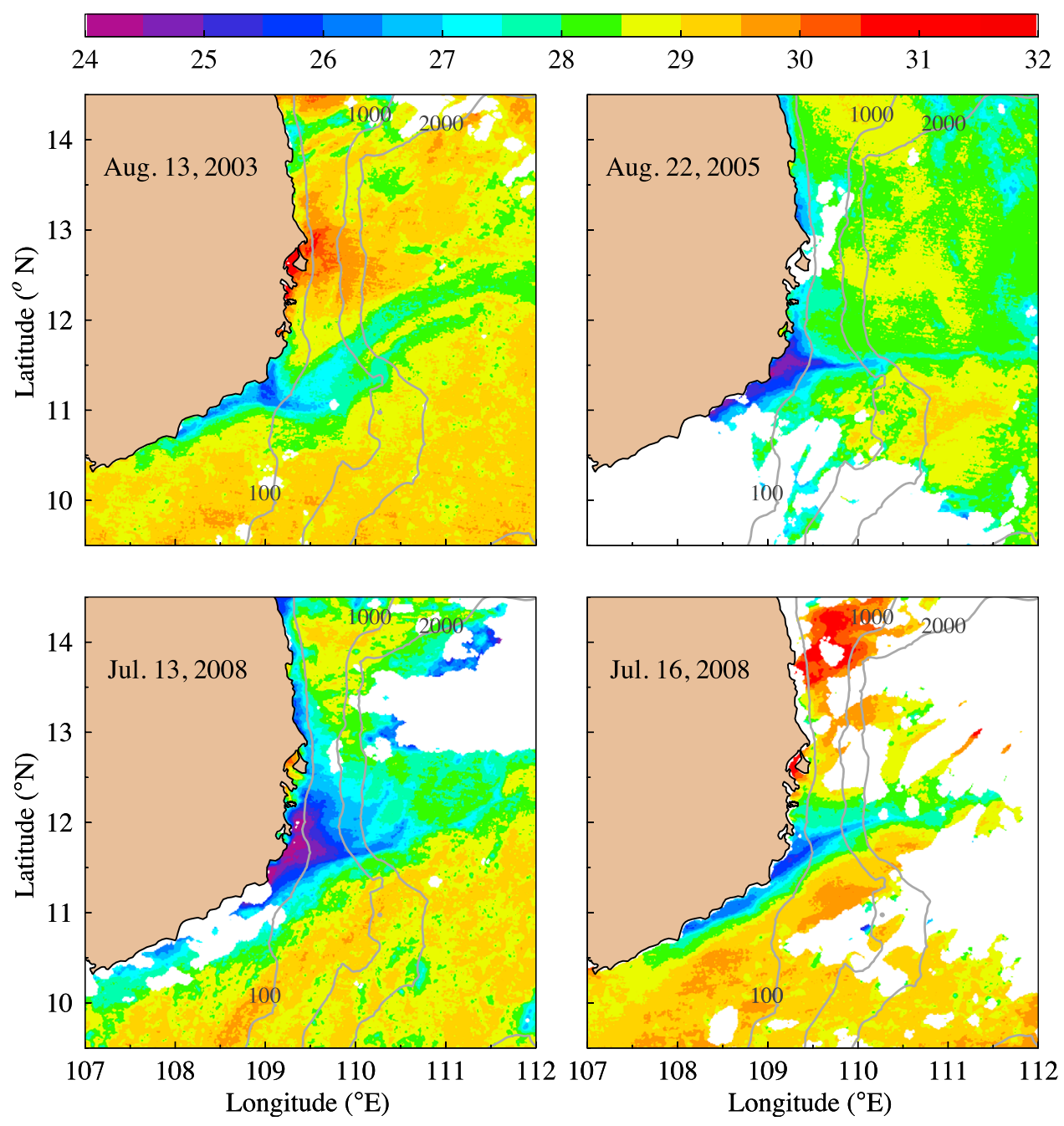

Figure 2. Satellite-derived SST images off the southeast coast of Vietnam on 13 August 2003, 22 August 2005 , 13 July 2008, and 16 July 2008. The satellite data were the L2 products of the Moderate Resolution Imaging Spectroradiometer (MODIS) downloaded from the NASA website (see http://oceancolor.gsfc. nasa.gov).

of a spatially uniform wind to upwelling could be estimated using a simple Ekman transport theory as follows. The August-averaged wind speed at the $10 \mathrm{~m}$ height in the study area (based on the 1995-2005 "blended" wind product) is $7.0 \mathrm{~m} / \mathrm{s}$. With a coastline angle of $70.6^{\circ}$ at $12^{\circ} \mathrm{N}$, the offshore Ekman transport per unit meter in the along-shelf direction is $\sim 1.94 \mathrm{~m}^{3} / \mathrm{s}$. Let $l_{w}$ be the cross-shelf scale of the upwelling zone with a typical value of $55 \mathrm{~km}$ (estimated from the satellite-derived SST images), then the vertical velocity over an area bounded by the cross-shelf width of $l_{w}$ and per unit meter along-shelf length is of order $3.5 \times$ $10^{-3} \mathrm{~cm} / \mathrm{s}$, which is about two times larger than the Ekman pumping rate estimated using the "blended" winds. This scaling analysis suggests that a spatially uniform wind is capable of producing the upwelling observed in summer from the satellite-derived SST images.

[6] As pointed out in previous studies, the rapid change of the coastline shape and local bathymetry over the southeast shelf of Vietnam play an important role in the formation of the current separation and upwelling. It is unclear, however, whether or not the dipole wind stress curl is a critical driving force to cause the offshore current separation. The southwesterly monsoon wind prevails in the SCS during the summer season [Wyrtki, 1961; Shaw and Chao, 1994; Chu et al., 1998, 1999; Shi et al., 2002; Yang et al., 2002]. Upwelling is, however, only significant in a limited area in the current separation zone (Figure 2). This suggests that there are other physical processes that cancel the upwellingfavorable wind effects in the upstream coastal area along eastern and northern Vietnam. The question here is: if these physical processes exist, could they contribute to the formation of the current separation zone in the downstream area around $11^{\circ}-12^{\circ} \mathrm{N}$ ?

[7] The SCS is characterized by strong tidal motion caused by the dominant $\mathrm{M}_{2}, \mathrm{~S}_{2}, \mathrm{~N}_{2}, \mathrm{~K}_{1}, \mathrm{O}_{1}$ and $\mathrm{P}_{1}$ constituents [Fang et al., 1999; Shi et al., 2002; Beardsley et al., 2004; Duda and Rainville, 2008]. Although the tidal currents are of order $10 \mathrm{~cm} / \mathrm{s}$ or less along the southern coast of Vietnam, tidal rectification, a nonlinear interaction process of tidal currents via bottom friction over abrupt changes in local bathymetry, can cause asymmetric tidal motion and thus produce a residual flow or jet along local topography 

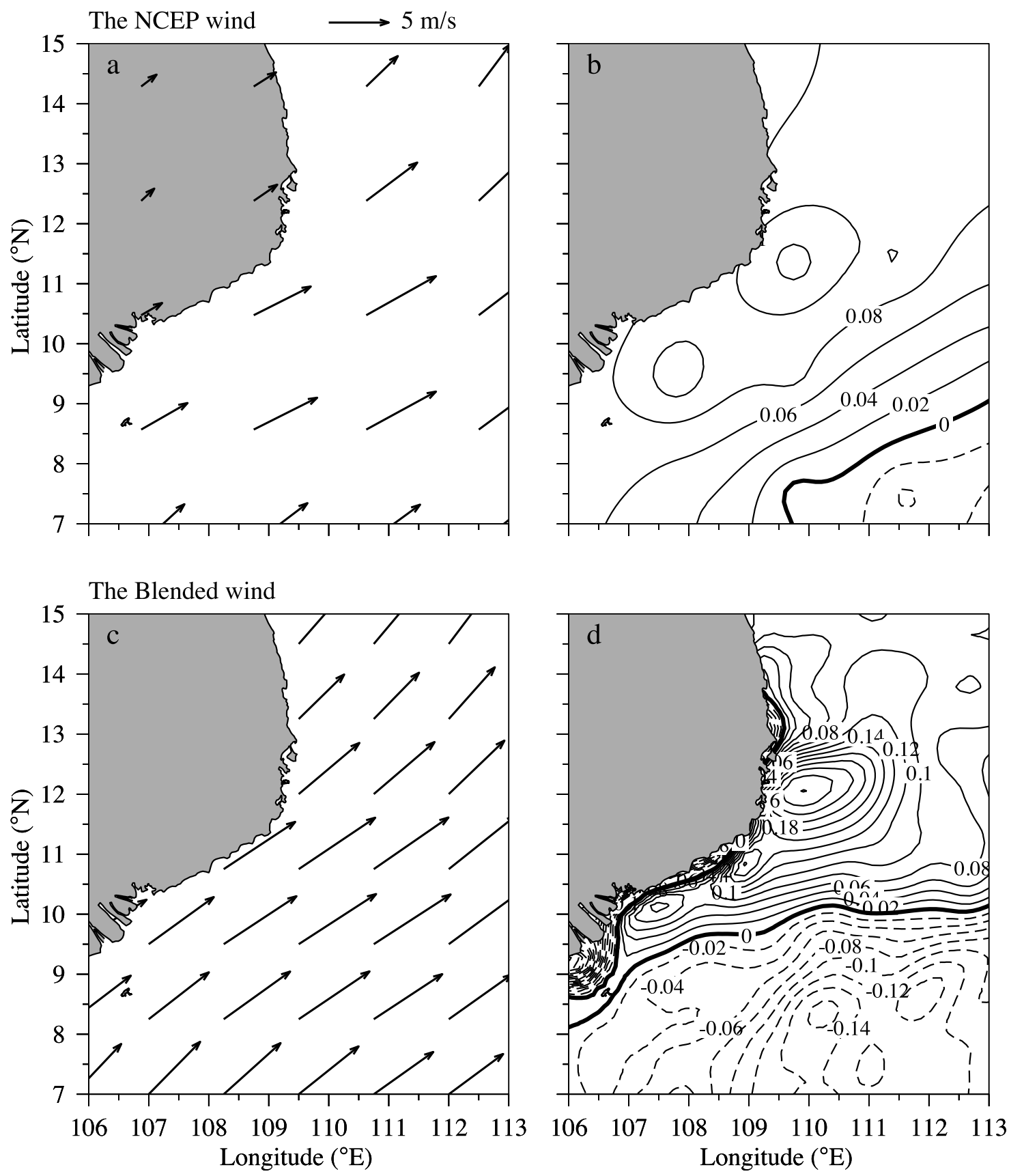

Figure 3. Distribution of the August monthly averaged wind velocity vectors at a height of $10 \mathrm{~m}$ and wind stress curl at the sea surface produced from $(a, b)$ the NCEP reanalysis and $(c, d)$ blended database.

[Huthnance, 1973; Loder, 1980; Shi et al., 2002]. When the water is stratified in summer, this residual current can be intensified along the slope as a result of stratified tidal rectification [Maas and Zimmerman, 1989; Chen and Beardsley, 1995, 1998]. Does this nonlinear tidal rectification process contribute to the current separation along the southeast coast of Vietnam?

[8] As a result of the monsoon climate, freshwater discharges from the Hong River in the Gulf of Tonkin in the north and the Mekong River in the south vary seasonally, with peaks in late summer (August-September). We have collected the hourly recorded discharge data of the Hong
River for the period 1972-1999 and in the Mekong River for 1996-2001. The monthly averaged discharge rates of the Mekong River (a sum of the data measured at the Hau and Tien stations) and of the Hong River (a sum of the data measured at the Hanoi and Sontay stations) exceeded $2.0 \times$ $10^{4} \mathrm{~m}^{3} / \mathrm{s}$ and $1.0 \times 10^{4} \mathrm{~m}^{3} / \mathrm{s}$ in late summer, respectively, with interannual variability in a range of $\sim 10^{4} \mathrm{~m}^{3} / \mathrm{s}$ (Figure 4).

[9] The freshwater discharge from the Hong River generates a river plume and subsequent southward buoyancydriven flow along the Vietnamese shelf. This flow is intensified during the summer as the river discharge increases. 


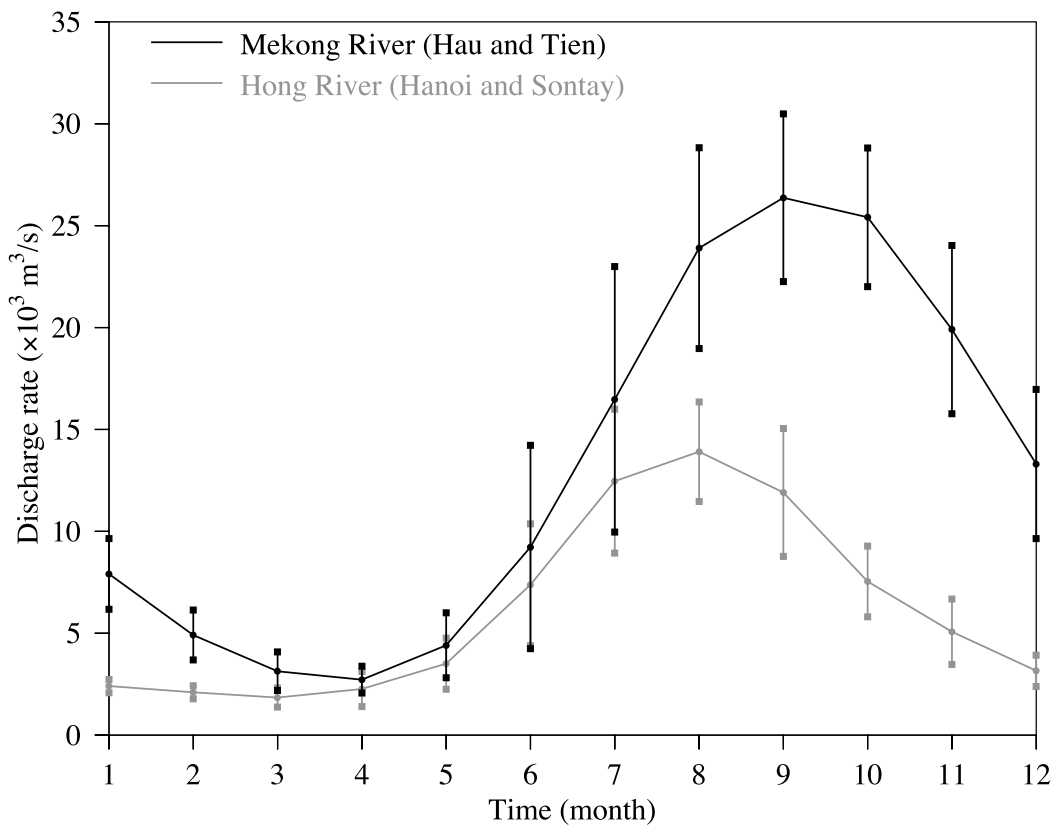

Figure 4. Seasonal cycle of monthly averaged river discharge from the Mekong and Hong rivers. The data used for the Mekong River are from the Hau and Tien stations with hourly records from 1996 to 2001. The data used for the Hong River are from the Hanoi and Sontay stations with hourly records from 1972 to 1999 (see Figure 1 for station locations). Vertical bars are the standard deviations of the river discharge relative to the mean over the measurement period.

Could the southward buoyancy flow associated with the river discharge contribute to the current separation along the southeast coast of Vietnam? In general, the river plume produced by the Mekong River discharge tends to extend southward along the coast. During southwesterly monsoon wind conditions, could this buoyancy-driven flow change its direction to flow northeastward and contribute to the offshore current separation? If this is a case, how is this feature related to tidal rectification and wind stress?

[10] We, a joint research team of the University of Massachusetts Dartmouth (UMASSD) and Woods Hole Oceanographic Institution (WHOI), have developed a highresolution, unstructured-grid, finite-volume China coastal model. This model was configured using FVCOM (version 3.1) with a computational domain covering the Japan/East Sea (JES), Bohai/Yellow/East China Sea (BY-ECS) and the SCS. The unstructured triangular grid used in FVCOM provides good resolution of the coastline and highly variable topography over the shelf and narrow slope in the SCS. The finite-volume algorithms guarantee local mass conservation in the sense of flux calculation, making it practical to examine the relative importance of various physical processes. Driven by tides, river discharge and winds separately, we have examined the physical mechanisms for the current separation and upwelling around the southeast coast of Vietnam. This study is aimed at identifying and understanding the contributions of various physical processes on this unique feature in that region.

[11] The rest of the paper is organized as follows. The China coastal FVCOM and design of the numerical experiments are described in section 2 . The model results for the cases driven by various forcing are presented in section 3 .
The physical mechanism is discussed in section 4, and conclusions are summarized in section 5 .

\section{Model and Design of Numerical Experiments}

[12] The China coastal FVCOM is a high-resolution, unstructured-grid, finite-volume, three-dimensional, free surface, primitive equation numerical model developed originally by Chen et al. [2003] and upgraded by the joint UMASSD-WHOI development team [Chen et al., 2006a, 2006b, 2007, 2009; Huang et al., 2008]. FVCOM is described in detail in the work of Chen et al. [2006b] and a brief summary of key modules used for this study is given here. We used a default setup of the modified Mellor and Yamada level 2.5 (MY-2.5) [Mellor and Yamada, 1982] and Smagorinsky [Smagorinsky, 1963] turbulent closure schemes for vertical and horizontal mixing, respectively. The governing equations in FVCOM is discretized by an integral form over control volumes in which the advection terms are solved by a second-order accuracy upwind finite volume flux scheme [Kobayashi et al., 1999; Hubbard, 1999] and time integration made using the modified explicit fourth-order Runge-Kutta (RK4) time stepping scheme. FVCOM is implemented with two solvers: (1) a mode-split solver in which external and internal modes are advanced in tandem at different time steps and (2) a semiimplicit solver with a single time step inversely proportional to water current magnitude. The experiments described in this paper were conducted using the mode-split solver.

[13] The computational domain covers the entire JES, BY-ECS and SCS (Figure 5) and is configured with the unstructured triangular grid. The horizontal resolution (defined as the longest side length of a triangle) varies over 


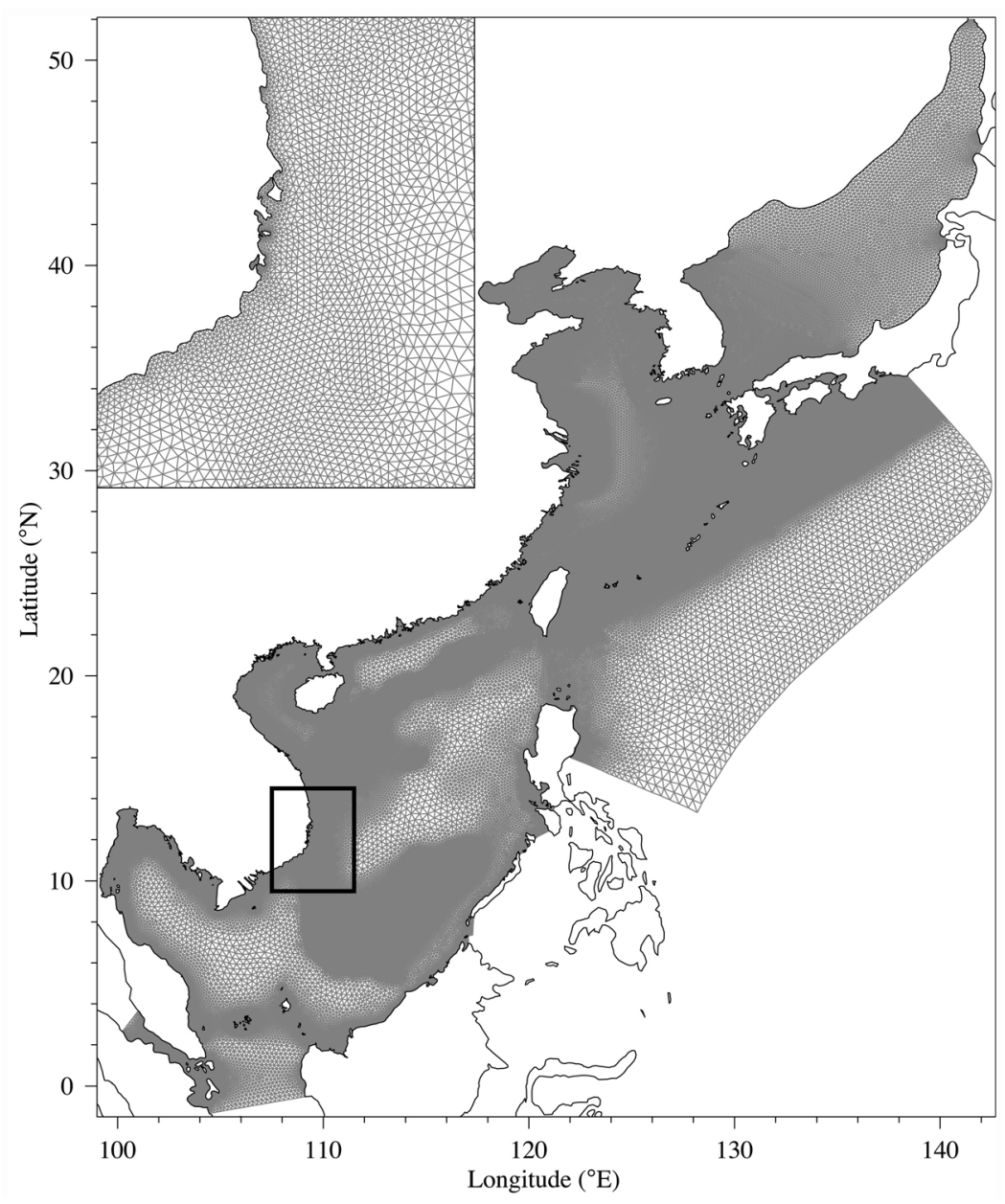

Figure 5. Unstructured triangular grid of the China coastal FVCOM. Inset box is the area where the grid in the subfigure is shown.

the range of $\sim 0.25-0.5 \mathrm{~km}$ in the inner shelf and estuaries, $\sim 0.7-0.8 \mathrm{~km}$ in the offshore region along the Vietnam coast and $\sim 35 \mathrm{~km}$ near the open boundary. A hybrid coordinate with a total of 40 layers is used in the vertical: an $s$ coordinate is used in the region of depth $>80.0 \mathrm{~m}$, with a transition at a depth of $80.0 \mathrm{~m}$ to a $\sigma$-coordinate in shallower areas. In the $s$ coordinate, five uniform layers with a thickness of $2.0 \mathrm{~m}$ are specified from the surface and bottom to resolve the surface mixed and bottom boundary layers over the slope. This produces a uniform thickness of $2 \mathrm{~m}$ for each layer at the $s$ and $\sigma$ coordinate transition and a vertical resolution of $2 \mathrm{~m}$ or less in the shallower regions.

[14] Numerical experiments were designed to address two questions: (1) How do the tidal rectification and river discharge-driven buoyancy flow contribute to the current separation?, and (2) What is the role of winds in upwelling? To answer the first question, we made two numerical experiments. First, the model was driven by only tidal forcing (constructed using tidal amplitudes and phases of the five major tidal constituents: $\mathrm{M}_{2}, \mathrm{~N}_{2}, \mathrm{~S}_{2}, \mathrm{O}_{1}$ and $\mathrm{K}_{1}$ ) at the open boundary to examine tidal dynamics and tidal rectification in homogenous conditions (Exp-I). Second, the model was run with tidal forcing and freshwater discharge from the rivers included in the computational domain (Exp-II). At the northern open boundaries in the Pacific
Ocean, the Kuroshio was built up with a transport inflow of $29.5 \mathrm{~Sv}$ on the southern open boundary on the eastern coast of Luzon Island, $26.9 \mathrm{~Sv}$ for the Kuroshio southeast of Japan, 1.6 Sv through the Tsugaru Strait, and 1.1 Sv through the Soya Strait [Chen et al., 2008]. Flow-through boundary conditions were applied at the two southern open boundaries (the Karimata and Malacca Straits). Although the Kuroshio is far away from the study area and has no direct dynamical impact on the current separation and upwelling over the southwest shelf of Vietnam [Shaw, 1991; Farris and Wimbush, 1996; Caruso et al., 2006], we included it to more accurately simulate the SCS regional background circulation.

[15] To answer the second question, we ran the model with inclusion of wind forcing in two ways. First, wind forcing was added into the spin-up forcing field in the case with tidal and river discharges (Exp-III). Two types of wind forcing were considered, a spatially uniform wind field and a monthly climatologically averaged wind field. The wind data used to build the climatology were from the multisatellite derived 6 hourly blended wind field gridded with a horizontal resolution of $0.25^{\circ} \times 0.25^{\circ}$ for the period 1995 2005 [Zhang et al., 2006]. Second, we conducted an experiment for the case with only wind forcing (Exp-IV). In 
Table 1. Comparisons Between Computed and Observed Tidal Elevations at Two Tidal Measurement Sites Over the Coast of Vietnam ${ }^{\mathrm{a}}$

\begin{tabular}{|c|c|c|c|c|c|c|}
\hline Tidal Constituent & $H_{o b s}(\mathrm{~cm})$ & $\left|H_{f v c o m}-H_{o b s}\right|(\mathrm{cm})$ & $\left|H_{F}-H_{o b s}\right|(\mathrm{cm})$ & $\theta_{o b s}\left({ }^{\circ}\right)$ & $\left|\theta_{f v c o m}-\theta_{o b s}\right|\left(^{\circ}\right)$ & $\left|\theta_{F}-\theta_{o b s}\right|\left({ }^{\circ}\right)$ \\
\hline \multicolumn{7}{|c|}{$\operatorname{Cam} \operatorname{Ranh}\left(11^{\circ} 53^{\prime}, 109^{\circ} 12^{\prime}\right)$} \\
\hline M2 & 18 & 1 & 1 & 329 & 7 & 7 \\
\hline $\mathrm{S} 2$ & 9 & 0 & 1 & 9 & 5 & 13 \\
\hline $\mathrm{K} 1$ & 34 & 4 & 1 & 307 & 3 & 1 \\
\hline $\mathrm{O} 1$ & 30 & 1 & 2 & 265 & 4 & 11 \\
\hline \multicolumn{7}{|c|}{ Vung Tau $\left(10^{\circ} 20^{\prime}, 107^{\circ} 04^{\prime}\right)$} \\
\hline $\mathrm{M}_{2}$ & 79 & 1 & 5 & 63 & 7 & 16 \\
\hline $\mathrm{S}_{2}$ & 30 & 0 & 8 & 111 & 7 & 17 \\
\hline $\mathrm{K}_{1}$ & 61 & 3 & 4 & 327 & 7 & 4 \\
\hline $\mathrm{O}_{1}$ & 46 & 0 & 4 & 277 & 6 & 9 \\
\hline
\end{tabular}

\footnotetext{
${ }^{\text {a Note that }} H_{o b s}$ and $\theta_{\text {obs }}$ are the observed tidal amplitude and phase, $H_{f v c o m}$ and $\theta_{f v c o m}$ are the FVCOM-computed tidal amplitude and phase, and $H_{F}$ and $\theta_{F}$ are the tidal amplitude and phase computed by Fang et al. [1999].
}

this case, we also considered both spatially uniform and nonuniform wind fields.

[16] For Exp-I, Exp-II and Exp-III, initial conditions of water temperature and salinity were specified using the August monthly climatologically averaged field. The monthly climatologic temperature and salinity fields were constructed using multiple sources: NOAA National Oceanographic Data Center (NODC) and individual hydrographic survey data provided by scientists from United States, Japan, South Korea and China. These data were processed using the following steps. In step 1, data from multiple sources were organized into a standard selfdescribed data format. In step 2, all profiles that were either vertically unstable or out of realistic range owing to temperature or salinity problems were removed. In step 3 , the remaining profiles were vertically interpolated to the standard layers and then gridded into nonoverlapping $20 \times 20 \mathrm{~km}$ boxes. This resolution provided a reasonably realistic climatology of water temperature and salinity over a large scale, but only poorly resolved hydrographic features over the coastal and continental margin region. The model hydrographic features in this region (which are predicted by prognostic integration) are the result of the adjustment of the ocean to external forcing (tides, coastal river discharge, and wind). For Exp-IV, the initial conditions of water temperature and salinity were specified using averaged fields with no horizontal gradients. This specification was designed to distinguish the roles of wind and buoyancy forcing in the current separation and upwelling.

\section{Process-Oriented Experiment Results}

\subsection{Tidal Rectification-Induced Current Separation}

[17] For Exp-I, the tidal simulation was a 90 day model run conducted without stratification and river discharge. The MATLAB harmonic analysis toolbox (T_Tide) [Pawlowicz et al., 2002] was used to calculate tidal constants (amplitude and phase) of the tidal elevation and ellipse parameters (major and minor axes, phase and orientation) of the tidal current for each tidal constituent. The model-predicted tidal constituents were compared directly with available tidal measurement data at 162 tidal gauges (99 in the BY-ECS and 63 in the SCS) [Choi, 1980; Fang et al., 1999]. The overall standard deviation errors for the SCS stations are in the same range with tidal simulations reported in previous structured-grid tidal model studies [Fang et al., 1999]. Our model provides a more accurate simulation of tidal elevation in the near-coastal region along the coast of Vietnam. An example for model-data comparison at Cam Ranh $\left(11^{\circ} 53^{\prime}\right.$, $\left.109^{\circ} 12^{\prime}\right)$ and Vung Tau (10 $20^{\prime} 109^{\circ} 04^{\prime}$; see Figure 1) are shown in Table 1.

[18] We next examined time series of the tidal currents over the southern shelf of Vietnam. The tidal currents are strongly asymmetrical over a tidal cycle in that region where bottom topographic contours diverge southward (Figure 6). At maximum ebb, the tidal currents move the water from the upstream north southward and the water from the downstream northeastward. As a result, these waters converge around $12^{\circ} \mathrm{N}$, producing an offshore current separation zone in the region where bottom topography varies abruptly. At ebb to flood transition, a cyclonic eddy forms in that region. The water moves southward along the shelf, turns offshore and then recirculates cyclonically in deeper water. At maximum flood, the entire area is dominated by tidal currents flowing southward parallel to the local bathymetry. At flood to ebb transition, an offshore current separation appears again, and the currents are stronger on the north than on the south. The asymmetry of tidal currents produces an offshore residual flow in the coastal region near $11.25^{\circ} \mathrm{N}$, which forms as a result of the southward current from upstream and a northeastward current from the downstream Mekong River area (Figure 7). This suggests that current separation along the southeast coast of Vietnam can occur as a result of tidal rectification without stratification, although the currents are weak and the location of this current separation has been shifted southward relative to those detected in the SST images shown in Figure 2. The key point here is that under a nonstratified condition with the absence of the southwesterly monsoon wind, tidal rectification can produce a northeastward along-shore residual current from the downstream region off the Mekong River.

\subsection{Buoyancy and Stratified Tidal Rectification-Induced Current Separation}

[19] In Exp-II, when river discharges are added and the initial temperature and salinity stratification is specified by the summer climatology, the model produces the welldefined current separation zone off the southeast coast of Vietnam, in which temperature shows a cold core starting near the coast and then extending offshore (Figure 8). This structure is similar to those observed in the summer satellitederived SST images. The southward current from the north 

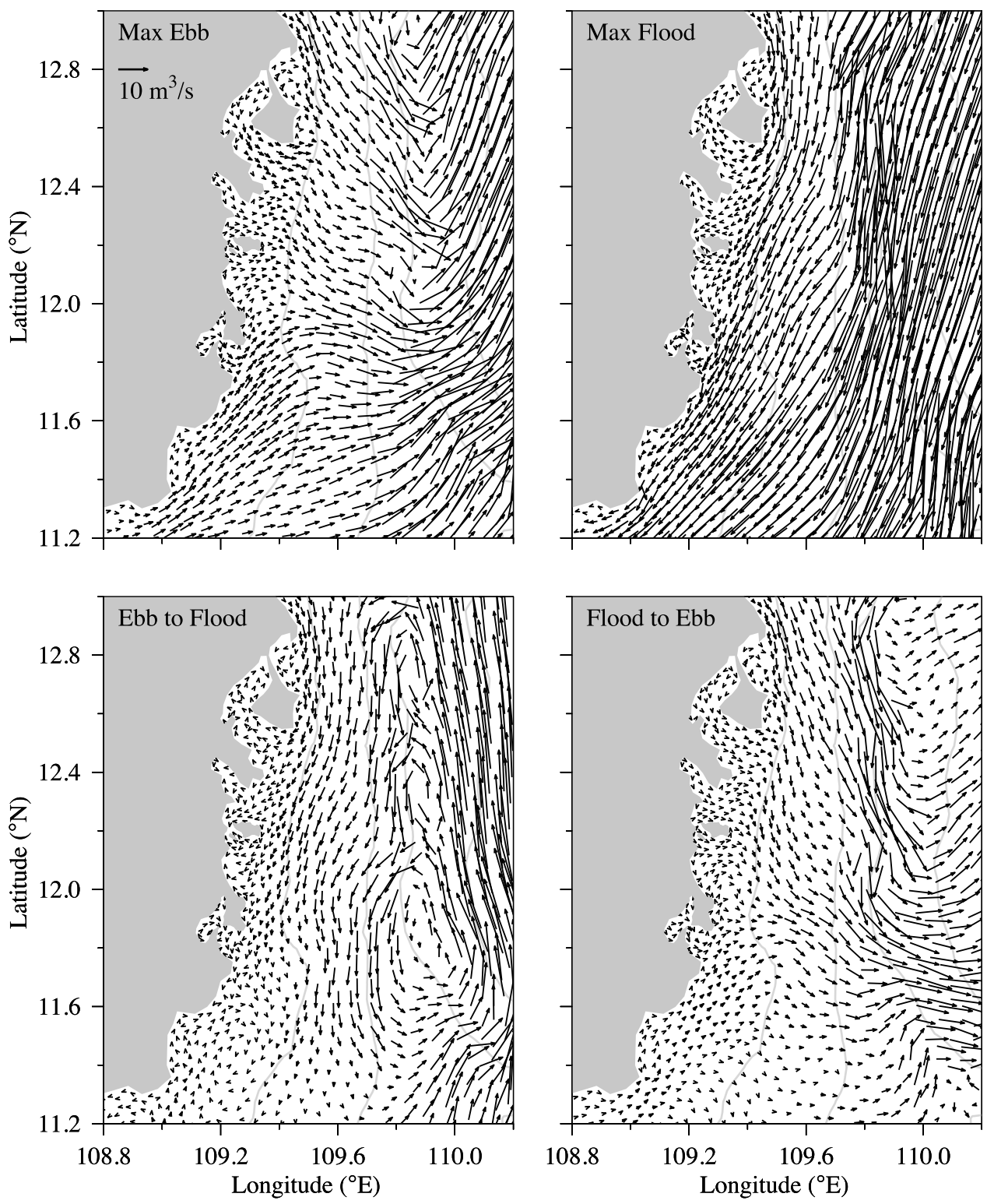

Figure 6. Spatial pattern of the model-computed vertically integrated tidal current (transport) vectors $\left(\mathrm{m}^{3} / \mathrm{s}\right)$ at maximum ebb, ebb to flood, maximum flood, and flood to ebb with no stratification.

is a well-defined coastal flow with speeds of $10-15 \mathrm{~cm} / \mathrm{s}$, which can be traced back to the Hong River discharge. The Mekong River discharge splits into two branches: one flowing southwestward along the coast and the other flowing northeastward along the coast toward $11^{\circ} \mathrm{N}$ where it meets the southward coastal current. The speed of these flows is of order $\sim 5-10 \mathrm{~cm} / \mathrm{s}$. This northeastward current is a result of stratified tidal rectification (see the discussion in the momentum balance): forming originally by tidal rectification and being intensified owing to stratification produced by the Mekong River discharge. The offshore current separation zone thus forms as a result of the encounter of the southward buoyancy-driven flow on the upstream north and the northeastward buoyancy and tidal rectified flow on the downstream south. The offshore transport in the separation zone is intensified as an anticyclonic flow from the southeastern area joins the offshore separation flow around the 100-1000 $\mathrm{m}$ isobaths.
[20] Our finding challenges the wind-driven mechanism proposed in previous studies. These model results suggest that the combination of tidal-rectified and buoyancy-driven flows is sufficient to generate an offshore current separation zone without wind forcing. While we understand that the southwesterly monsoon winds play an important role in the summertime circulation in this region, our results suggest a new physical mechanism for the offshore current separation observed off the southeast coast of Vietnam.

\subsection{Effects of Winds}

\subsubsection{Case With Tides and River Discharges}

[21] In Exp-III, we ran the model by adding wind forcing to the tidally and buoyancy- driven simulation described above. Two wind cases are considered: (1) a spatially uniform constant wind and (2) the August monthly climatologically averaged wind field obtained using the 1995-2005 


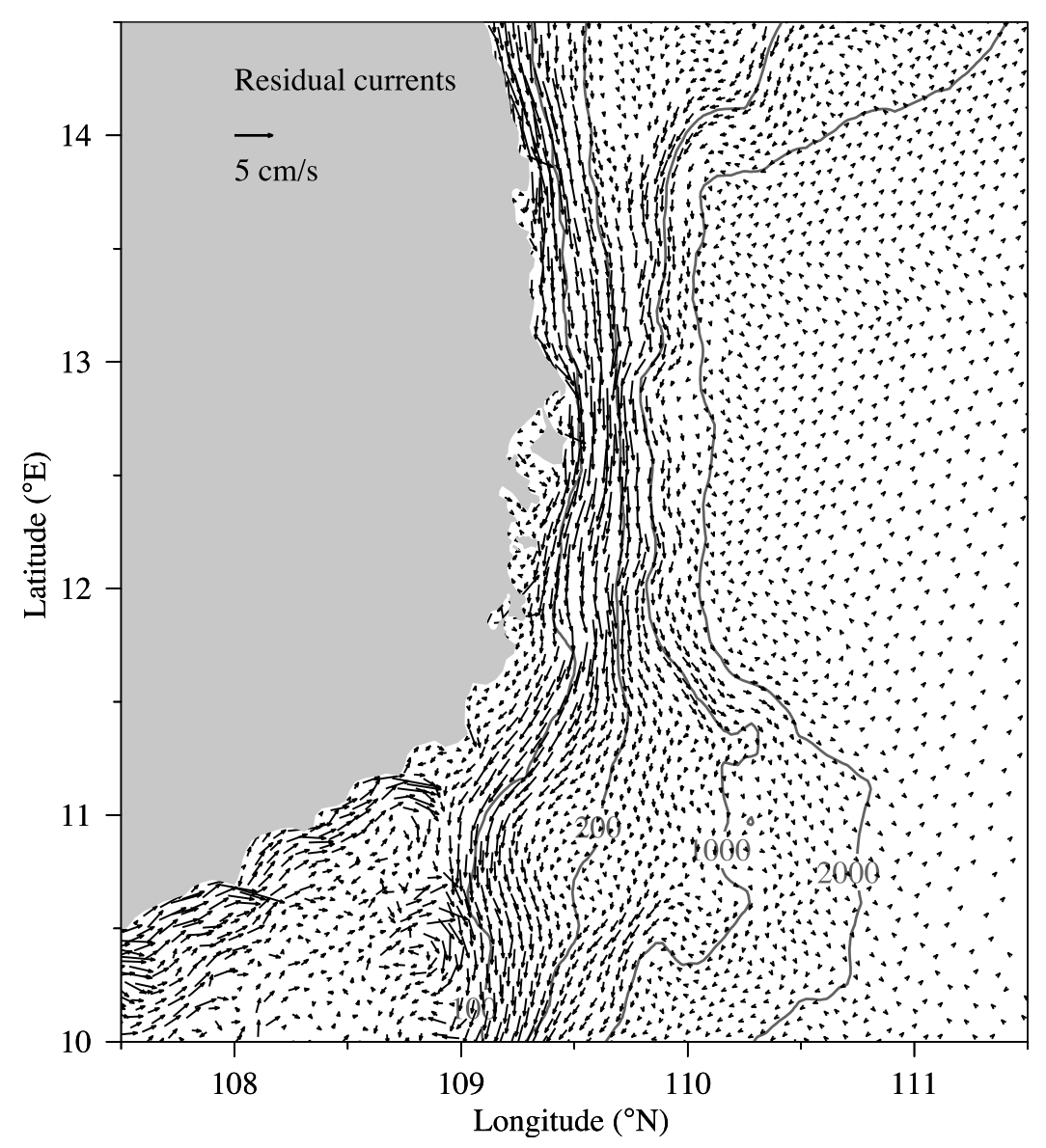

Figure 7. Distribution of the model-computed near-surface residual current $(\mathrm{cm} / \mathrm{s})$ with no stratification. The tidal currents were removed using the MATLAB harmonic analysis toolbox (T_Tide) by Pawlowicz et al. [2002].

satellite-derived blended wind field. The spatially uniform wind field is specified by a $10 \mathrm{~m}$ wind velocity of $5.63 \mathrm{~m} / \mathrm{s}$ toward the east and $4.16 \mathrm{~m} / \mathrm{s}$ toward the north, which is the mean August wind velocity in the center of the current separation zone.

[22] These model experiments with wind forcing show that the northeastward monsoon wind is an important mechanism to intensify upwelling in the current separation zone during the summer season. Both constant and spatially varying winds significantly intensify the offshore current separation and thus upwelling (Figure 9). As a result, near the sea surface in the current separation zone, the water temperature drops about $\sim 2-3^{\circ} \mathrm{C}$ and the offshore velocity increases to $\sim 30 \mathrm{~cm} / \mathrm{s}(\sim 10 \mathrm{~cm} / \mathrm{s}$ larger than that observed in the case without wind forcing). No significant difference was found in the magnitude of water velocity between these two cases, but the upwelling zone near the coast is much wider in the constant wind-forcing case. Defining the temperature contour of $25.5^{\circ}$ as the boundary of the primary upwelling zone, the difference of the area between the two cases is about $8.6 \times 10^{3} \mathrm{~km}^{2}$. This result is consistent with the distribution of the spatially varying wind stress curl (Figure 3d), which shows a negative curl near the coast in the upstream area of the current separation zone. The negative curl produces a downward Ekman pumping-induced transport that tends to cancel the upward transport associated with the wind-induced offshore Ekman flow. This fact suggests that the dipole surface wind stress curl plays an important role in determining the spatial distribution of the wind-driven upwelling but is not the essential mechanism for upwelling.

[23] The contribution of wind forcing to local upwelling can be seen clearly in the comparison of the cross-isobath temperature distributions in the cases with and without winds (Figure 10). Without wind forcing, the offshore current separation is clearly defined but upwelling is weak. In this case, the maximum vertical velocity in the coldest surface water area is $\sim 1.1 \times 10^{-3} \mathrm{~cm} / \mathrm{s}$ : a value that is larger than the upwelling value estimated using the NCEP wind stress curl and is similar to that found using the blended wind stress curl. When the monsoon wind forcing is added, the offshore Ekman transport moves the water in the upper water column offshore, with a compensating upward transport over the shelf and upper slope. In this case, the maximum vertical velocity is up to $\sim 1.1 \times 10^{-2} \mathrm{~cm} / \mathrm{s}$ : one order of magnitude larger than that in the no-wind case. In addition, the cross-isobath current in the upwelling zone features double circulation cells. In the upper $65 \mathrm{~m}$, water is advected toward the coast and then upward and offshore, creating a deep surface mixed layer of colder water. In the deeper region, water tends to move up the slope to $\sim 100 \mathrm{~m}$ isobaths before slowing significantly. This flow structure suggests 


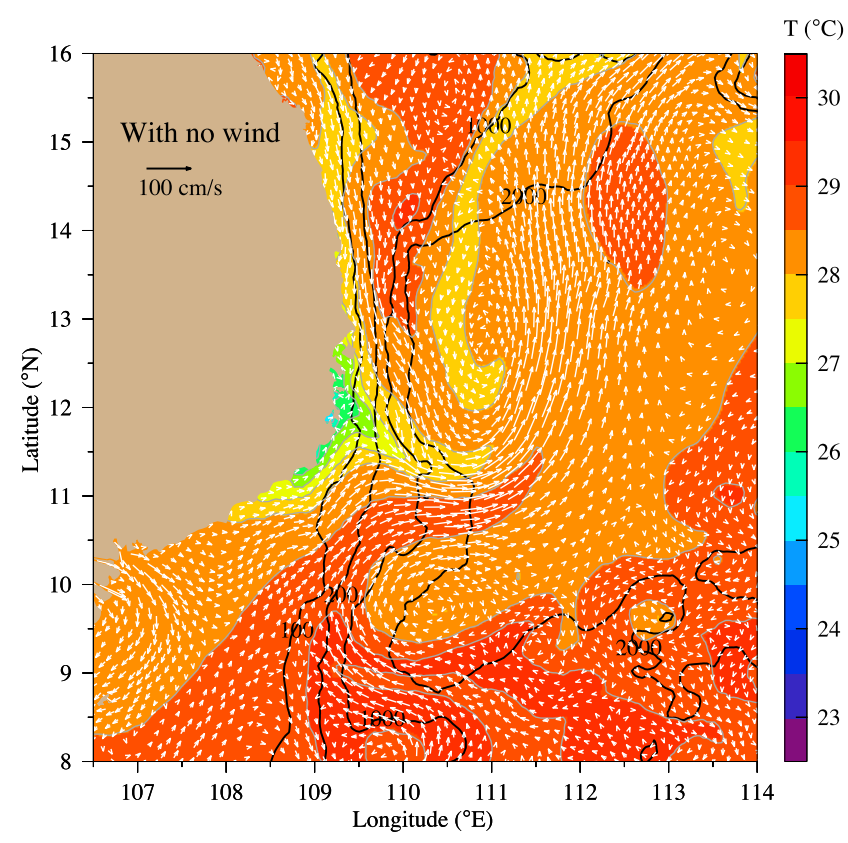

Figure 8. Model-computed near-surface subtidal current vectors $(\mathrm{cm} / \mathrm{s})$ plotted on the surface temperature field at the 40th day of the spin-up run, starting with August climatology temperature and salinity fields for the case with no wind. Black lines are the contours of 100, 200, 1000, and $2000 \mathrm{~m}$ isobaths.

that the wind-induced upwelled surface water is from the upper water column, rather than from the bottom boundary layer over the slope.

[24] The subtidally averaged mean sea surface height (SSH) remains the same pattern in the cases without and with wind forcing (Figure 11). The model-computed large-scale
SSH pattern is similar to that derived from the TOPEX/ POSEIDON altimeter-derived SSH described by Shaw et al. [1999]. The altimeter-derived SSH data described in the work of Shaw et al. [1999] were obtained with a spatial sampling resolution of $40 \mathrm{~km}$, which prevents it from providing the detailed structure in the coastal region shown in Figure 11. Divided by the axis of maximum offshore current in the current separation zone, the mean sea level is characterized by a north-south elongated depression in the north and an offshore-increasing gradient in the south. With the geostrophic tendency for barotropic currents to follow sea level contours, the sea level pattern matches well with the circulation pattern shown in Figure 8: cyclonic in the north and anticyclonic in the south. Adding wind forcing does not reverse the surface elevation distribution except increasing the gradient near the coast in the anticyclonic flow zone and offshore in the cyclonic flow zone. The maximum SSH gradient is $\sim 6.7 \times 10^{-7}$ for the case without wind forcing and up to $\sim 1.3 \times 10^{-6}$ and $\sim 1.5 \times 10^{-6}$ for the cases with varying and spatially uniform wind forcing, respectively. Although the stratified tidal and buoyancy-driven currents are dominant in this area, the sea level offshore gradient cannot be ignored in the formation of the current separation zone. In addition, the distribution of the offshore subtidal sea level gradient off the Mekong River is consistent with the splitting of currents there: a southwest flow to the south and a northeast flow to the north.

\subsubsection{Case With Only Wind Forcing}

[25] One question raised in this study is whether or not the southwesterly monsoon wind is sufficient to form the observed current separation and upwelling. Theoretically speaking, the southwesterly wind tends to move the water offshore near the surface through the Ekman transport process and thus produce upwelling near the coast. Since the southwesterly wind prevails over the entire SCS, upwelling should appear along the coast of Vietnam. It is hard to
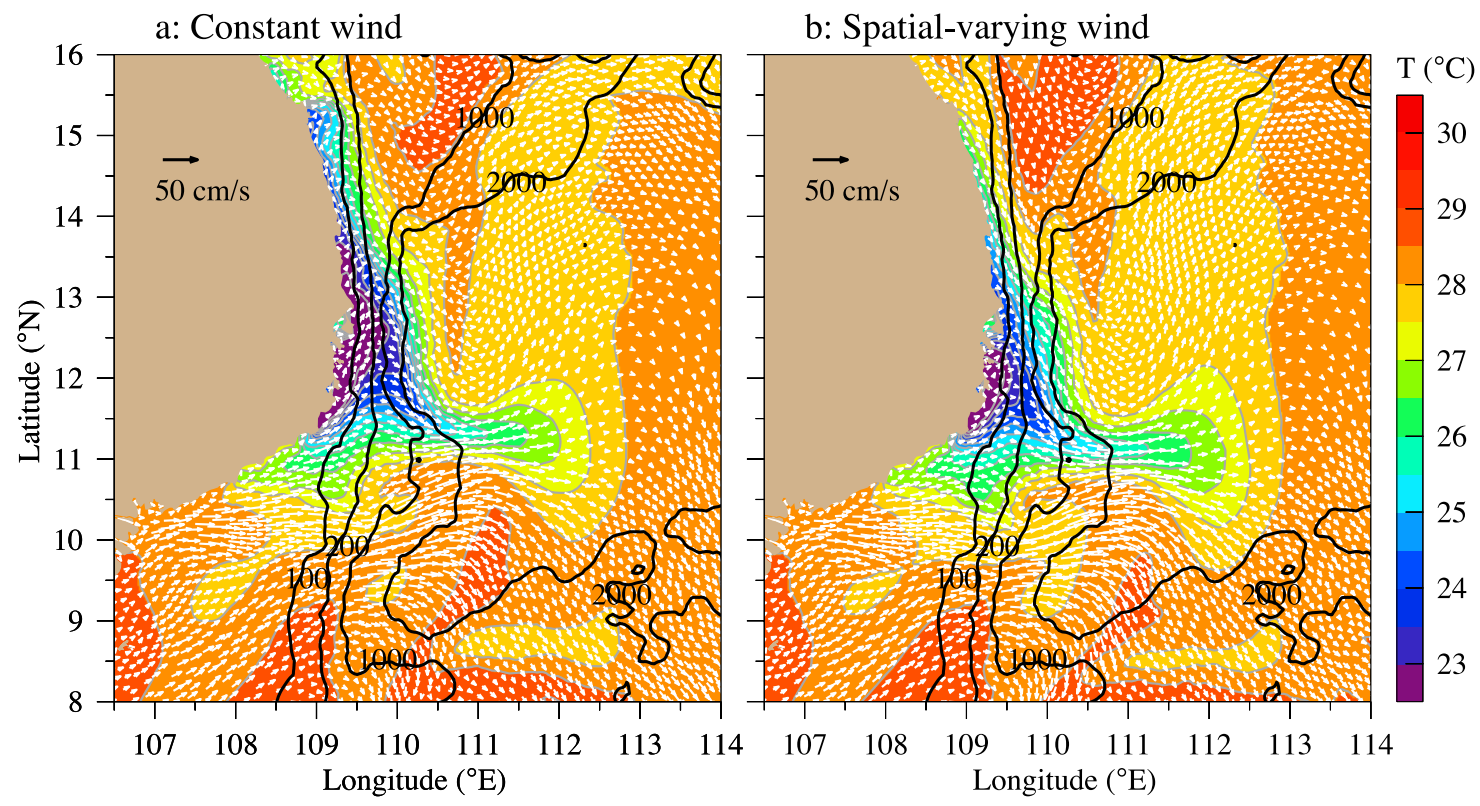

Figure 9. Model-computed near-surface subtidal current vectors $(\mathrm{cm} / \mathrm{s})$ plotted on the surface temperature field at the 10th day after (a) a spatially uniform wind and (b) a spatially varying wind are added. Black lines are the contours of 100, 200, 1000, and $2000 \mathrm{~m}$ isobaths. 


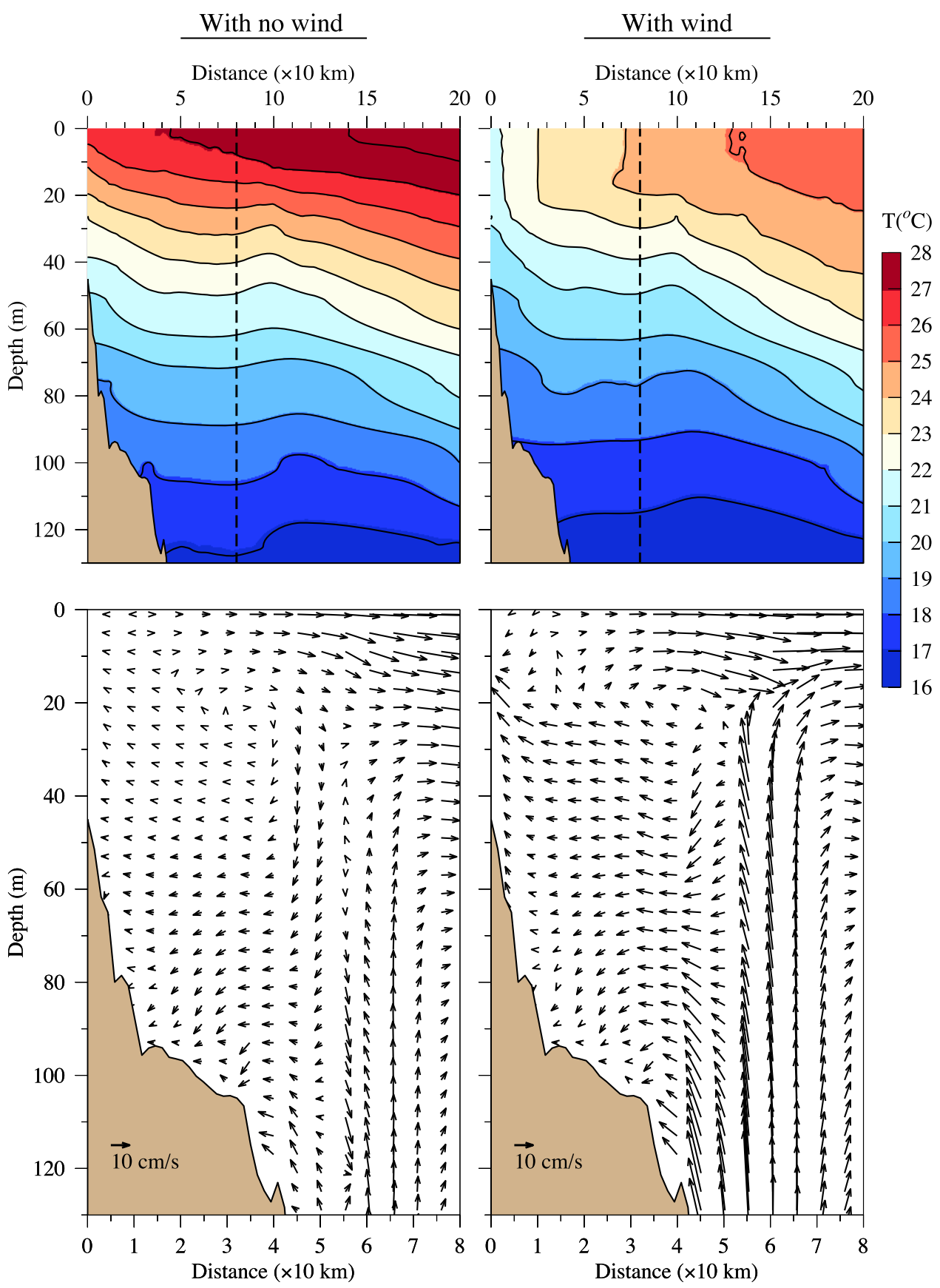

Figure 10. Cross-isobath distributions of model-computed (top) water temperature and (bottom) velocity $(\mathrm{cm} / \mathrm{s})$ on the section parallel to the direction of the offshore current in the separation zone (see Figure 1 for section location) for the cases without and with wind forcing. Dashed vertical lines indicate the offshore boundary used to draw the velocity. The vertical velocity is scaled by a factor of $10^{3}$ to match the vertical and horizontal scales.

imagine, however, that wind forcing alone could generate the current separation pattern shown in Figure 8. Exp-IV was designed to evaluate the contribution of wind forcing to the current separation and upwelling over the southwest coast of Vietnam. The wind forcing used to drive the model are the same as those used in Exp-III.

[26] For the case with spatially uniform wind forcing, the model predicts a strong northeastward or northward flow over the southwest shelf of Vietnam (Figure 12a). The flow tends to turn clockwise after entering the interior basin. The model does show a well-defined upwelling zone with a water temperature difference of $\sim 2^{\circ} \mathrm{C}$ along the coast, but no narrow current separation zone is found. Using the spatially varying wind forcing, the offshore flow in the region to the north of $12^{\circ} \mathrm{N}$ is significantly smaller (about $10-15 \mathrm{~cm} / \mathrm{s}$ smaller), even though the direction of the flow remains little changed. As in the spatially uniform wind case, no narrow current separation zone is generated. In this case, the 

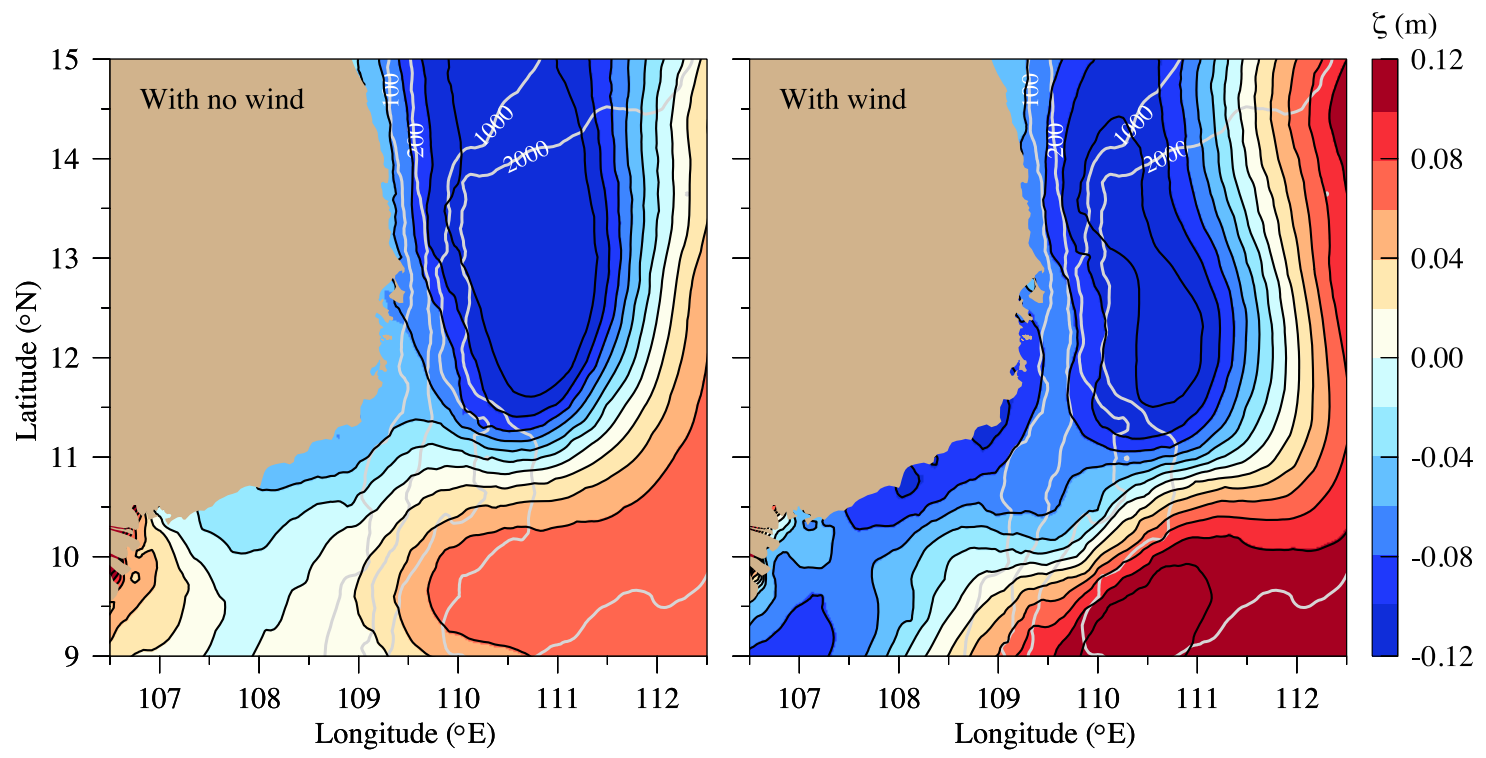

Figure 11. Model-computed daily averaged subtidal sea surface elevation on the 40th day of the spin-up run for the case without wind forcing and the 10th day after the spatially varying wind forcing is added. White lines are the 100, 200, 1000, and $2000 \mathrm{~m}$ depth contours.

significant upwelling zone shrinks to a smaller area around $12^{\circ} \mathrm{N}$. These results support our findings gained from Exp-III, in which we illustrated that upwelling can be generated by spatially uniform wind forcing and the surface wind stress curl contributes directly to the spatial scale of upwelling in that area.

\section{Momentum Balance Analyses}

[27] To study the physical mechanism of current separation and upwelling along the southeast coast of Vietnam, we examined the momentum balance for the cases without and

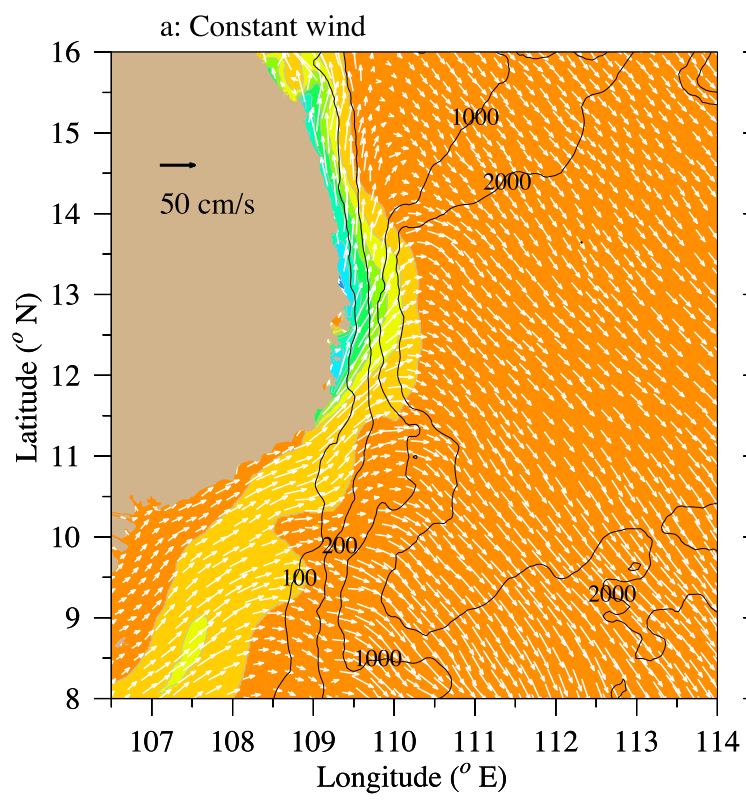

with wind forcing. Defining that $x$ is the cross-shelf axis (positive offshore) and $y$ is the along-shelf axis (positive northward) of the local Cartesian coordinate system, the $x$ and $y$ momentum equations can be written as

$$
\begin{gathered}
-f v+g \frac{\partial \zeta}{\partial x}+\frac{1}{\rho} \frac{\partial P}{\partial x}+\vec{v} \cdot \nabla u+w \frac{\partial u}{\partial z}-\frac{\partial}{\partial z}\left(K_{m} \frac{\partial u}{\partial z}\right)+\frac{\partial u}{\partial t}=0 \\
f u+g \frac{\partial \zeta}{\partial y}+\frac{1}{\rho} \frac{\partial P}{\partial y}+\vec{v} \cdot \nabla v+w \frac{\partial v}{\partial z}-\frac{\partial}{\partial z}\left(K_{m} \frac{\partial v}{\partial z}\right)+\frac{\partial v}{\partial t}=0
\end{gathered}
$$

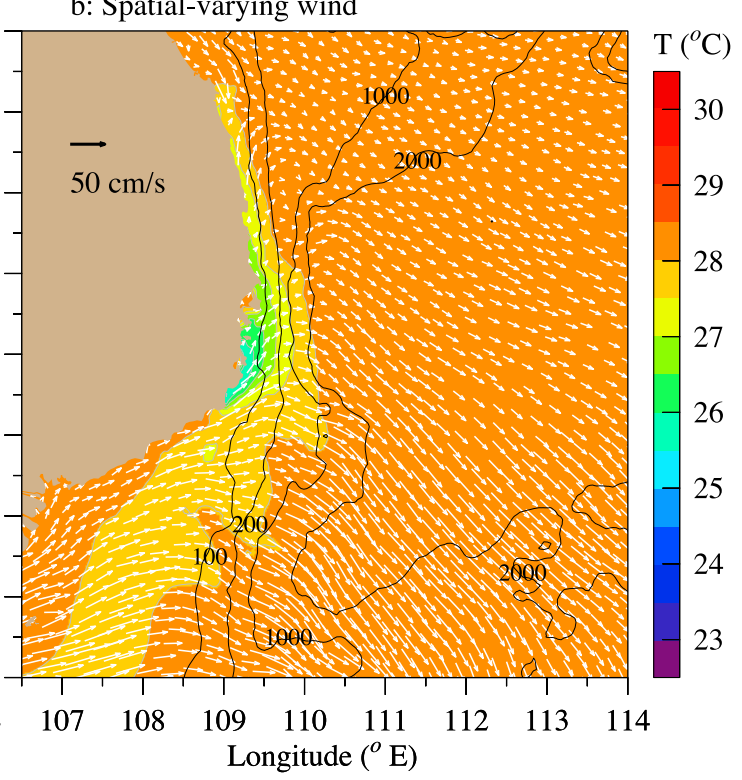

Figure 12. Model-computed near-surface subtidal current vectors $(\mathrm{cm} / \mathrm{s})$ plotted on the surface temperature field at the 10th model day for the cases with only wind forcing. (a) A spatially uniform wind case. (b) A spatially varying wind case. Black lines are the contours of 100, 200, 1000, and $2000 \mathrm{~m}$ isobaths. The vectors were selected over a distance of 0.15 degrees in these two plots. 

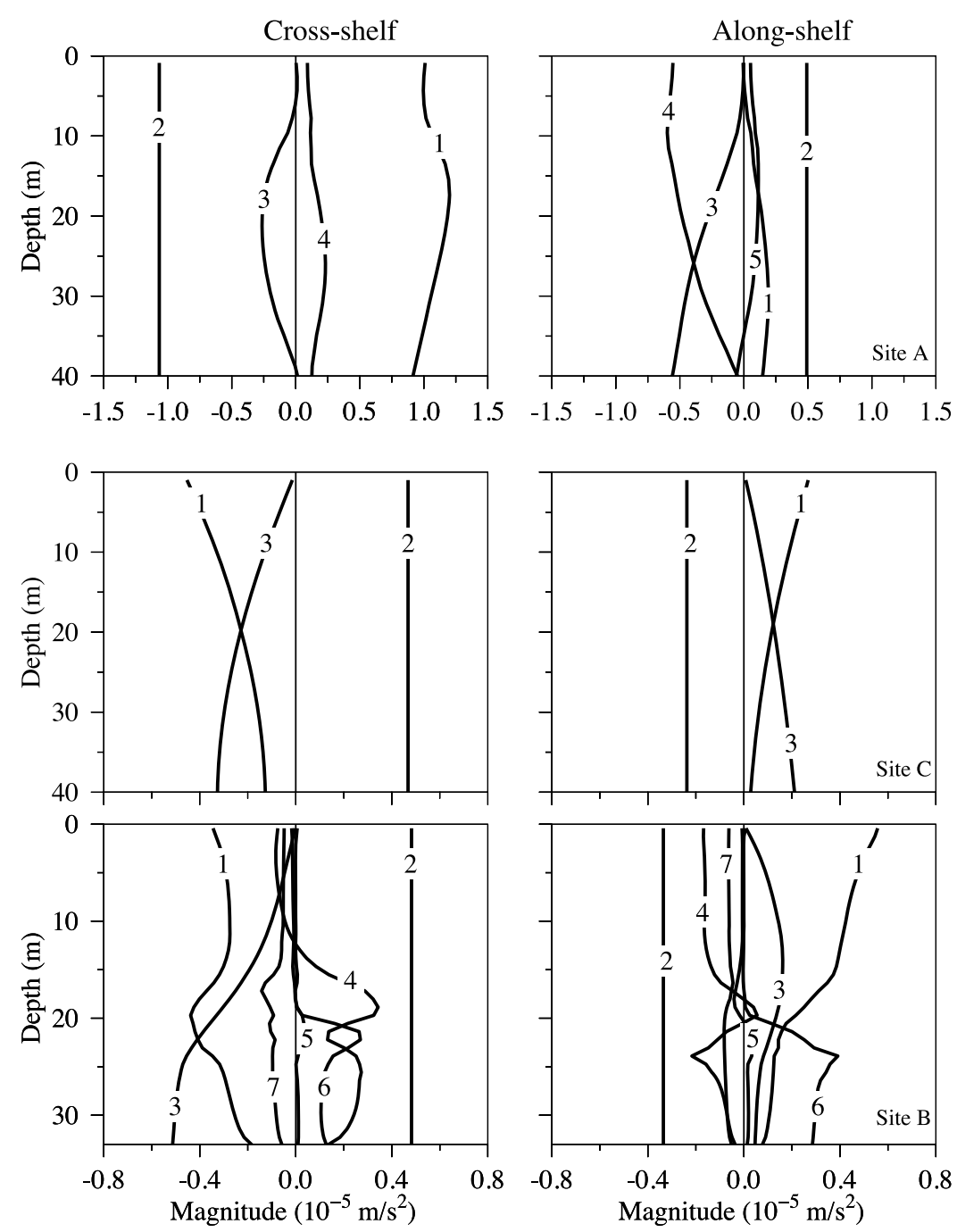

Figure 13. Vertical profiles of the daily averaged terms of the momentum equations in the cross- and along-shelf directions on the 40th day of the spin-up run at (top) site A, (middle) site C, and (bottom) site $\mathrm{B}$ for the case with no wind forcing. Numbers represent the following: 1, Coriolis force; 2, surface elevation gradient; 3, baroclinic pressure gradient; 4, horizontal advection; 5, vertical advection; 6 , vertical diffusion; and 7, acceleration.

where $u, v$ and $w$ are the $x, y$ and $z$ components of the water velocity; $f$ is the Coriolis parameter; $\zeta$ is the surface elevation; $P$ is the baroclinic pressure; $\rho$ is the water density; $K_{m}$ is the vertical viscosity; and $t$ is the time. To simplify the discussion, we name the terms on the left side of each equation using the numbers from 1 to 7 .

[28] For the case without winds, Figure 13 shows the cross-shelf and along-shelf momentum balances at site A (within the southward coastal flow from the north), at site C (in the current separation zone) and at site B (in the northeastward flow from the downstream south off the northern outlet of the Mekong River), respectively. The locations of these three sites are marked in Figure 1.

[29] At site A, the flow features a semigeostrophic current. In the cross-shelf momentum equation, the southward alongshelf flow satisfies a quasi-geostrophic condition in which the cross-shelf surface elevation gradient force is mainly balanced by the Coriolis force, with first-order contributions from the baroclinic pressure gradient and horizontal advection (see Figure 13). In the along-shelf momentum equation, the flow is controlled by a complex nonlinear process in which horizontal advection, surface and baroclinic pressure gradients, the Coriolis force, and vertical diffusion are all in the same order of magnitude.

[30] At site B, in the cross-shelf momentum equation, a northeastward along-shelf flow occupies throughout the water column. However, the dynamics controlling this flow differs in the vertical. In the upper $15 \mathrm{~m}$ water column, the flow is dominated by a geostrophic current with a balance between the Coriolis and surface pressure gradient forces. In the lower water column beneath depths of $15 \mathrm{~m}$, however, the northeastward along-shelf flow is controlled by an unsteady, fully nonlinear physical process in which horizontal advection, vertical diffusion, the Coriolis force, surface pressure gradient force and baroclinic pressure gradient force are important. The largest terms still are the surface and baroclinic pressure gradient forces, so that the flow is dominated by the geostrophic flow. However, the nonlinear 

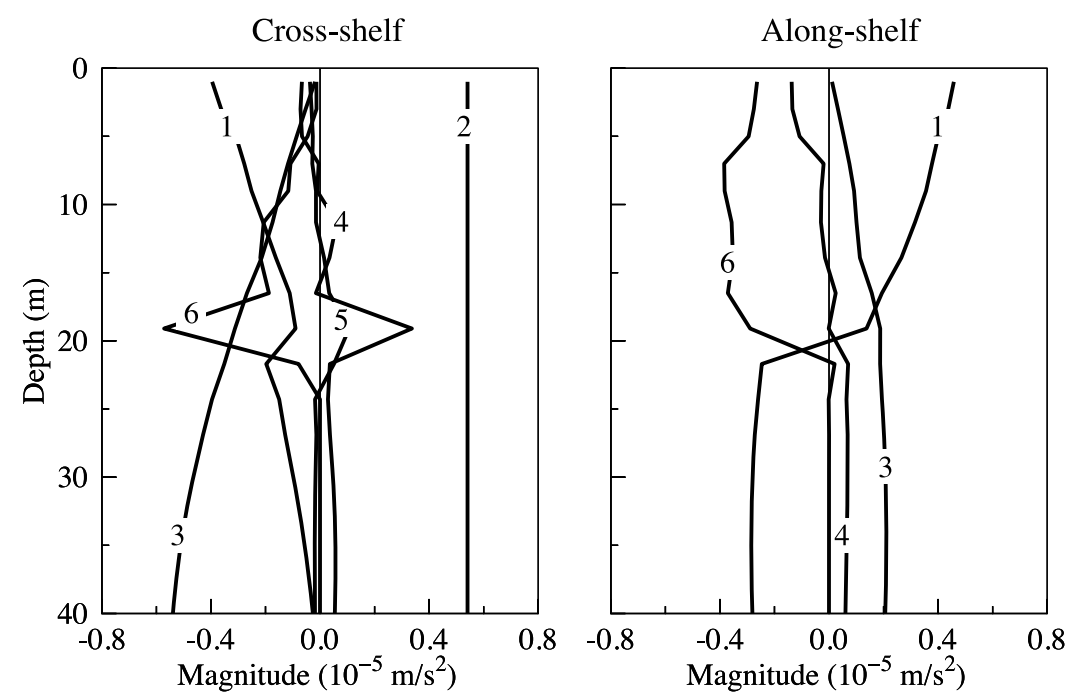

Figure 14. Vertical profiles of the daily averaged terms of the momentum equations in the cross-and along-shelf directions at site $\mathrm{C}$ on the 10th day after the wind forcing is added. The terms are identified by number as in Figure 13.

horizontal advection and vertical diffusion terms also have their maximum values in the lower water column, which suggests that stratified tidal rectification also plays an important role in generating the northeastward along-shelf flow. This is consistent with the theoretical finding by Chen and Beardsley [1995] that stratified tidal rectification caused by tidal mixing, enhanced divergence or convergence of the tidal momentum flux, and modification of internal diffusion via stratification can lead to a subsurface intensification of the along-isobath residual flow. In the along-shelf momentum equation, the whole water column features an offshore flow: stronger in the upper $15 \mathrm{~m}$ water column and decreases rapidly with depth in the lower water column. The dynamics controlling this offshore flow also differs in the upper and lower water columns. In the upper water column, it is driven by the surface pressure gradient force and convergence of the momentum flux against the baroclinic pressure gradient force. In the lower water column, it is driven under a momentum balance between the surface pressure gradient force, vertical diffusion and horizontal advection.

[31] At site $\mathrm{C}$, the flow is dominated by a linear geostrophic current with a balance between the surface elevation gradient, baroclinic pressure gradient and Coriolis forces. This offshore current forms as the encounter of the buoyancydriven southward along-shelf geostrophic current from the north and the northeastward buoyancy-driven and stratified tidal-rectified current from the south.

[32] Adding wind forcing does not change the dynamical balances at sites $\mathrm{A}$ and $\mathrm{B}$. At site $\mathrm{C}$ where the strong upwelling is predicted, however, the flow in the upper $20 \mathrm{~m}$ water column is characterized by nonlinear ageostrophic dynamics In the cross-shelf momentum equation, although the along-shelf flow near the surface is still primarily a geostrophic current, nonlinear processes play an essential role in the momentum balance in the subsurface where the maximum upwelling is predicted. This is evident in Figure 14 (left), where the horizontal/vertical advection and vertical diffusion show maximum peaks at a depth of $20 \mathrm{~m}$.
The momentum balance in the along-shelf momentum equation (Figure 14, right) shows a two-layer flow feature: offshore in the upper $20 \mathrm{~m}$ water column and inshore in the deeper region. The wind significantly enhances vertical mixing in the upper water column, and the offshore flow in that layer is driven by vertical diffusion and divergence of momentum flux against the baroclinic pressure gradient force. In the lower layer where the wind influence is weak or vanishes, the inshore flow is driven by the baroclinic pressure gradient force against the convergence of the momentum flux.

\section{Conclusions and Discussion}

[33] We have examined the physical mechanisms that cause the current separation and upwelling observed over the southeast shelf of Vietnam in the South China Sea. Processoriented numerical experiments with the high-resolution China coastal FVCOM suggest that the offshore current separation in summer can be caused by the meeting of a buoyancy-driven southward along-shelf quasi-geostrophic coastal current from the north and a northeastward buoyancydriven and stratified tidal-rectified current from the southwest. In this case, tidal rectification, river discharge and local bathymetry all play critical roles in intensifying these two coastal currents during summertime stratified conditions.

[34] There is always a northeastward current from the southeastern mouth of the Mekong River as a result of tidal rectification. This flow can be intensified significantly by the large river discharge and southwesterly monsoon wind forcing during the summer season. As a result, water in this area off the Mekong River moves northeastward. The dynamics controlling this current are fully nonlinear, with significant contributions from advection and vertical diffusion.

[35] The southward flow from the north is primarily a coastal current that can be traced upstream to the Hong River in the Gulf of Tonkin. This current is dominated by quasi- 
linear geostrophic dynamics and mostly confined to the narrow shelf along the northern Vietnamese coast.

[36] The southwesterly monsoon wind forcing is a key physical process to generate upwelling, but it is not a prerequisite to cause the narrow offshore current separation in that area. This upwelling can be caused by a spatially uniform wind following a simple wind-induced Ekman transport theory. The dipole wind stress curl is not a dominant process to drive upwelling, but it does control the spatial scale of upwelling. The model driven with a wind stress, river discharge and tides under summertime stratified conditions is capable of reproducing the location and tonguelike offshore distribution of temperature as those seen in the satellite-derived SST images.

[37] Previous modeling studies (described in section 1) conclude that the offshore current separation and upwelling observed in summer off the southeast Vietnam coast are driven by the dipole surface wind stress curl associated with the monsoon winds. Our results, however, suggest that wind forcing is not a necessary condition to produce the offshore current separation zone but does play an essential role in producing upwelling. It is unclear if river discharge was included in the previous modeling studies. Owing to the computational limitations, the previous numerical experiments were made using relatively coarse resolution models with a horizontal resolution of $\sim 10 \mathrm{~km}$ or larger. Such coarse resolution models poorly simulate nearshore processes, particularly in and near the Mekong River estuary, where the tidally rectified and buoyancy-intensified northeastward current exists. Our studies suggest that it is critical to resolve the nearshore physical processes if one attempts to understand the physical mechanisms driving the current separation over the southeast coast of Vietnam in the South China Sea.

[38] It should be noted here that this process study focused on the current separation and upwelling off the Vietnam coast observed during summer conditions. Previous basinscale model and theoretical studies suggest that the pronounced seasonal variability of the observed basin-scale circulation in the SCS is driven primarily by the East Asian monsoon, with strong southwesterly surface winds in winter and slightly weaker northeasterly winds in summer. Liu et al. [2001] showed that the SCS basin response time to wind curl-induced baroclinic Rossby waves is sufficiently short ( $1-4$ months) that the seasonal circulation is in quasi-equilibrium with the monsoon wind cycle. Fang et al. [2009] used a global model with higher $\left(1 / 6^{\circ} \times 1 / 6^{\circ}\right)$ resolution in the JES, BY-ECS, SCS, and the Indonesian Seas to show that the monsoon wind cycle also drives an observed reversal in the Pacific-to-Indian Ocean throughflow, with net flow into (out of) the southern SCS through the Karimata and Malacca Straits during the summer (winter) monsoon wind forcing. The summer inflow transport was relatively weak $(\sim 1 \mathrm{~Sv})$ and appears to have little effect in the circulation near the Vietnam southeast coast [Yang et al., 2002]. To understand how these seasonal changes in the SCS forcing and circulation may influence the current separation and upwelling occurring in late summer (August) off Vietnam examined in this paper will require a model system that includes sufficient spatial and temporal resolution to capture the dominant coastal processes (e.g., tides, river discharge, shelf-basin exchange, coastal wind forcing, etc.) and their variability on synopticto-seasonal time scales.

[39] Acknowledgments. This work was supported by an Office of Naval Research grant through a subcontract from the Woods Hole Oceanographic Institution (WHOI). We thank Glen G. Gawarkiewicz at WHOI, who invited us to participate in his ONR South China Sea project, and we value frequent discussions with him about this work. We also thank our Vietnamese collaborators who spent significant time on helping collect the freshwater discharge data and shared their opinions on the accuracy of local bathymetry measurements, as well as Peter Zhu at the Naval Postgraduate School for sharing his experiences in the SCS modeling. We also want to acknowledge the useful feedback provided by three anonymous reviewers, which helped improve this manuscript.The development of FVCOM was supported by the NSF Ocean Sciences Division through grants OCE-0234545, OCE-0227679, OCE-0606928, OCE-0712903, OCE0726851, and OCE-0814505; the NSF Office of Polar Programs-Arctic Sciences Division through grants ARC0712903, ARC0732084, and ARC0804029; MIT Sea Grant projects 2006-RC-103 and 2010-R/RC116; and the NOAA NERACOOS program for the UMASS Dartmouth team. C. Chen's contribution is also supported by the Shanghai Ocean University International Cooperation Program (A-2302-11-0003), the Program of Science and Technology Commission of Shanghai Municipality (09320503700), the Leading Academic Discipline Project of Shanghai Municipal Education Commission (project J50702), and Zhi Jiang Scholar and 111 project funds of the State Key Laboratory for Estuarine and Coastal Research, East China Normal University. Z. Lai's contribution is supported by the China MOST Project 2012CB956004 SYSU 985, grant 42000-3181302.

\section{References}

Beardsley, R. C., T. F. Duda, J. F. Lynch, J. D. Irish, S. R. Ramp, C. S. Chiu, T. Y. Tang, Y. J. Yang, and G. H. Fang (2004), Barotropic tide in the northeast South China Sea, IEEE J. Oceanic Eng., 29, 1075-1086, doi:10.1109/JOE.2004.833226.

Caruso, M., G. G. Gawarkiewicz, and R. C. Beardsley (2006), Interannual variability of the Kuroshio intrusion in the South China Sea, J. Oceanogr., 62, 559-575, doi:10.1007/s10872-006-0076-0.

Chen, C., and R. C. Beardsley (1995), A numerical study of stratified tidal rectification over finite-amplitude banks, Part I: Symmetric banks, J. Phys. Oceanogr., 25, 2090-2110, doi:10.1175/1520-0485(1995)025<2090: ANSOST $>2.0 . \mathrm{CO} ; 2$.

Chen, C., and R. C. Beardsley (1998), Tidal mixing over finite-amplitude banks: A model study with application to Georges Bank, J. Mar. Res., 56, 1163-1201, doi:10.1357/002224098765093607.

Chen, C., H. Liu, and R. C. Beardsley (2003), An unstructured grid, finitevolume, three dimensional, primitive equations ocean model: Application to coastal ocean and estuaries, J. Atmos. Oceanic Technol., 20, 159-186, doi:10.1175/1520-0426(2003)020<0159:AUGFVT>2.0.CO;2.

Chen, C., R. C. Beardsley, and G. Cowles (2006a), An unstructured grid, finite-volume coastal ocean model (FVCOM) system, Oceanography, 19, 78-89, doi:10.5670/oceanog.2006.92.

Chen, C., G. Cowles, and R. C. Beardsley (2006b), An unstructured grid, finite-volume coastal ocean model: FVCOM user manual, 2nd ed., Tech Rep. 06-0602, 315 pp., Univ. of Mass. Dartmouth, Fairhaven.

Chen, C., H. Huang, R. C. Beardsley, H. Liu, Q. Xu, and G. Cowles (2007) A finite volume numerical approach for coastal ocean circulation studies: Comparisons with finite difference models, J. Geophys. Res., 112, C03018, doi:10.1029/2006JC003485.

Chen, C., et al. (2008), Physical mechanism for the offshore detachment of the Changjiang diluted water in the East China Sea, J. Geophys. Res., 113, C02002, doi:10.1029/2006JC003994.

Chen, C., P. Malanotte-Rizzoli, J. Wei, R. C. Beardsley, Z. Lai, P. Xue, S. Lyu, Q. Xu, J. Qi, and G. W. Cowles (2009), Application and comparison of Kalman filters for coastal ocean problems: An experiment with FVCOM, J. Geophys. Res., 114, C05011, doi:10.1029/2007JC004548.

Choi, B. H. (1980), A tidal model of the Yellow Sea and the Eastern China Sea, Rep. 80-02, 72 pp., Korea Ocean Res. and Dev. Inst., Ansan, South Korea.

Chu, P. C., Y. Chen, and S. Lu (1998), Wind-driven South China Sea deep basin warm-core and cool-core eddies, J. Oceanogr., 54, 347-360, doi:10.1007/BF02742619.

Chu, P. C., N. L. Edmons, and C. Fang (1999), Dynamical mechanism for the South China Sea seasonal circulation and thermohaline variabilities, J. Phys. Oceanogr., 29, 2971-2989, doi:10.1175/1520-0485(1999) 029<2971:DMFTSC $>2.0 . \mathrm{CO} ; 2$ 
Doktorgrades, Z. E. (2008), Vietnam upwelling: Analysis of the upwelling and related processes in the coastal area off South Vietnam, Ph.D. dissertation, 163 pp., Hamburg Univ., Hamburg, Germany.

Duda, T. F., and L. Rainville (2008), Diurnal and semidiurnal internal tide energy flux at a continental slope in the South China Sea, J. Geophys. Res., 113, C03025, doi:10.1029/2007JC004418.

Fang, G., Y. K. Kwok, K. J. Yu, and Y. H. Zhu (1999), Numerical simulation of principal tidal constituents in the South China Sea, Gulf of Tonkin and Gulf of Thailand, Cont. Shelf Res., 19, 845-869, doi:10.1016/S02784343(99)00002-3.

Fang, G., Y. Wang, Z. Wei, Y. Fang, F. Qiao, and X. Hu (2009), Interocean circulation and heat and freshwater budgets of the South China Sea based on a numerical model, Dyn. Atmos. Oceans, 47, 55-72, doi:10.1016/j. dynatmoce.2008.09.003

Farris, A., and M. Wimbush (1996), Wind-induced Kuroshio intrusion into the South China Sea, J. Oceanogr., 52, 771-784, doi:10.1007/ BF02239465

Gan, J. P., and T. D. Qu (2008), Coastal jet separation and associated flow variability in the southwest South China Sea, Deep Sea Res., Part I, 55 , 1-19, doi:10.1016/j.dsr.2007.09.008.

Hai, D. N., N. N. Lam, and J. W. Dippner (2010), Development of Phaeocystis globosa blooms in the upwelling waters of the south central coast of Vietnam, J. Mar. Sci., 83, 253-261, doi:10.1016/j.jmarsys. 2010.04.015.

Huang, H., C. Chen, G. W. Cowles, C. D. Winant, R. C. Beardsley, K. S. Hedstrom, and D. B. Haidvogel (2008), FVCOM validation experiments: Comparisons with ROMS for three idealized barotropic test problems, J. Geophys. Res., 113, C07042, doi:10.1029/2007JC004557.

Hubbard, M. E. (1999), Multidimensional slope limiters for MUSCL-type finite volume schemes on unstructured grids, J. Comput. Phys., 155, 54-74, doi:10.1006/jcph.1999.6329

Huthnance, J. M. (1973), Tidal current asymmetries over the Norfolk Sandbank, Estuarine Coastal Mar. Sci., 1, 89-99, doi:10.1016/0302-3524(73) 90061-3.

Kobayashi, M. H., J. M. C. Pereira, and J. C. F. Pereira (1999), A conservative finite-volume second-order-accurate projection method on hybrid unstructured grids, J. Comput. Phys., 150, 40-75, doi:10.1006/ jcph.1998.6163.

Liu, Z., H. J. Yang, and Q. Y. Liu (2001), Regional dynamics of seasonal variability of sea surface height in the South China Sea, J. Phys. Oceanogr. 31, 272-284, doi:10.1175/1520-0485(2001)031<0272:RDOSVI>2.0.CO;2.

Loder, J. W. (1980), Topographic rectification of tidal currents on the sides of Georges Bank, J. Phys. Oceanogr., 10, 1399-1416, doi:10.1175/1520 0485(1980)010<1399:TROTCO >2.0.CO;2.

Maas, L. R. M., and J. T. F. Zimmerman (1989), Tide-topography interaction in a stratified shelf sea, II: Bottom trapped internal tides and baroclinic residual currents, Geophys. Astrophys. Fluid Dyn., 45, 37-69, doi:10.1080/03091928908208892.
Mellor, G. L., and T. Yamada (1982), Development of a turbulence closure model for geophysical fluid problem, Rev. Geophys., 20, 851-875, doi:10.1029/RG020i004p00851.

Pawlowicz, R., R. C. Beardsley, and S. Lentz (2002), Classical tidal harmonic analysis with error analysis in MATLAB using T_TIDE, Comput. Geosci., 28, 929-937, doi:10.1016/S0098-3004(02)00013-4.

Shaw, P. T. (1991), The seasonal variation of the intrusion of the Philippine Sea water into the South China Sea, J. Geophys. Res., 96, 821-827, doi:10.1029/90JC02367.

Shaw, P. T., and S. Y. Chao (1994), Surface circulation in the South China Sea, Deep Sea Res., 41, 1663-1683, doi:10.1016/0967-0637(94)90067-1.

Shaw, P. T., S. Y. Chao, and L. L. Fu (1999), Sea surface height variations in the South China Sea from satellite altimetry, Oceanol. Acta, 22, 1-17, doi:10.1016/S0399-1784(99)80028-0.

Shi, M. C., C. Chen, Q. Xu, H. Lin, G. Liu, and H. Wang (2002), The role of Qiongzhou Strait in the seasonal variation of the South China Sea circulation, J. Phys. Oceanogr., 32, 103-121, doi:10.1175/1520-0485 (2002)032<0103:TROQSI $>2.0 . \mathrm{CO} ; 2$

Smagorinsky, J. (1963), General circulation experiments with the primitive equations, I. The basic experiment, Mon. Weather Rev., 91, 99-164, doi:10.1175/1520-0493(1963)091<0099:GCEWTP>2.3.CO;2.

Tang, D. L., H. Kawamura, T. V. Dien, and M. A. Lee (2004), Offshore phytoplankton biomass increase and its oceanographic causes in the South China Sea, Mar. Ecol. Prog. Ser., 268, 31-41, doi:10.3354/ meps 268031

Wyrtki, K. (1961), Physical Oceanography of the Southeast Asian Waters, Naga Report 2, Scientific Results of Marine Investigations of the South China Sea and the Gulf of Thailand, 195 pp., Scripps Inst. of Oceanogr. La Jolla, Calif.

Xie, S. P., Q. Xie, D. X. Wang, and W. T. Liu (2003), Summer upwelling in the South China Sea and its role in regional climate variations, J. Geophys. Res., 108(C8), 3261, doi:10.1029/2003JC001867.

Yang, H., Q. Liu, Z. Liu, D. Wang, and X. Liu (2002), A general circulation model study of the dynamics of the upper ocean circulation of the South China Sea, J. Geophys. Res., 107(C7), 3085, doi:10.1029/2001JC001084.

Zhang, H.-M., J. J. Bates, and R. W. Reynolds (2006), Assessment of composite global sampling: Sea surface wind speed, Geophys. Res. Lett., 33 L17714, doi:10.1029/2006GL027086.

R. C. Beardsley, Department of Physical Oceanography, Woods Hole Oceanographic Institution, Woods Hole, MA 02543, USA

C. Chen, Z. Lai, H. Lin, and Q. Xu, School for Marine Science and Technology, University of Massachusetts Dartmouth, New Bedford, MA 02748, USA. (c1chen@umassd.edu)

N. T. Viet, Department of Civil Engineering, Water Resource University, Hanoi, Vietnam. 